\title{
THE EARLY CARBONIFEROUS PALEOMAGNETIC FIELD OF NORTH AMERICA AND ITS BEARING ON TECTONICS OF THE NORTHERN APPALACHIANS
}

\author{
DENNIS V KENT and NEIL D OPDYKE \\ Lamont-Doherty Geological Observatory of Columbıa University, Palısades, NY 10964 (US A)
}

Recelved March 19, 1979

Revised version recerved May 4, 1979

\begin{abstract}
We have obtained additional evidence for the Early Carboniferous paleomagnetic field for cratonc North Amer$1 \mathrm{ca}$ from study of the Barnett Formation of central Texas A characteristic magnetization of this unit was 1solated after thermal demagnetization at four sites (36 samples) out of eight sites (65 samples) collected The mean direction of declination $=1563^{\circ}$, inclination $=58^{\circ}\left(N=4, k=905, \alpha_{95}=30^{\circ}\right)$, corresponds to a paleomagnetic pole position at lat $=491^{\circ} \mathrm{N}$, long $=1193^{\circ} \mathrm{E}\left(d p=15^{\circ}, d m=30^{\circ}\right)$ Field evidence suggests that characteristic magnetization was acquired very early in the history of the rock unit whereas the rejected sites are comprised of weakly magnetized limestones dominated by secondary components near the present-day field direction Comparison of the Barnett pole with other Early Carboniferous (Mississippian) paleopoles from North America shows that it lies close to the apparent polar wander path for stable North America and that the divergence of paleopoles from the Northern Appalachians noted previously for the Devonian persisted into the Early Carboniferous We interpret this difference in paleopoles as further evidence for the Northern Appalachian displaced terrain which we refer to here as Acadia, and the apparent coherence of Late Carboniferous paleopoles as indicatıng a large $(\sim 1500 \mathrm{~km})$ motion of Acadia with respect to stable North America over a rather short time interval in the Carboniferous
\end{abstract}

\section{Introduction}

One of the best ways to determine large-scale displacements between ancient contınental crustal blocks is by comparison of paleomagnetic pole positions In an earlier paper [1] we interpreted a systematic difference in Devonian paleomagnetic poles between the coastal New England-Canadian Maritime region and the now contiguous part of North America as evidence for about a $1500-\mathrm{km}$ relative tectonic displacement We consider the New England-Maritıme region to form part of a displaced terrain, herein referred to as Acadia This terrain apparently reached its present position relative to stable North Amenca sometime before the end of the Paleozorc, probably by the Late Carboniferous judging from the coherence of paleomagnetic poles of this age However, there are few reliable paleomagnetic data for Carboniferous rocks from stable North Amenca for comparison with Acadia, and therefore the timing of the relative mo- tion is not well constrained

We have studied the Barnett Formation of central Texas in an effort to document better the Lower Carboniferous (Mississippian) paleomagnetic field for stable North America An earlier paleomagnetic study of these rocks by Howell and Martınez [2] did not include any demagnetization analysis Although their data indicate the presence of a stable component of magnetization that differs from the present-day geomagnetic field direction, it is difficult to assess the importance of contributions from secondary magnet1zation in the absence of laboratory stability studies Consequently the derived paleomagnetic pole position reported by these authors may not be representative of the Mississippian North American pole position

\section{Geology and sampling}

The Barnett Formation crops out as part of the relatively thin Paleozoic sedimentary cover on the 
periphery of a dome-shaped upwarp of a Precambrian igneous and metamorphic complex This structural feature, referred to as the Llano Uplift, is located in central Texas, and tectonically is situated inboard of the Ouachita foldbelt that lies to the east and south To the north the Wichita Mountains represent a late Paleozoic orogen produced by reactivation of a Late Proterozolc aulocogen [3] However, there is no ev1dence of major displacements parallel to or across the Wichita system and the Liano Uplift area can therefore be considered an integral part of the North Amer1can craton during the Phanerozolc

The Barnett Formation in its type locality near San Saba is typically aboui $15 \mathrm{~m}$ thick and consists largely of brown shale, with characteristic large ellipsoidal limy concretions in the lower portion of the formation and calcareous, phosphatic and glauconitic strata in the upper 2-5 $\mathrm{m}$ However, in the southwestern and southeastern periphery of the Llano area rocks mapped as the Barnett Formation consist mostly of limestone [4] Biostratigraphic studies indicate the Barnett Formation is of Mississippian (Osage to perhaps Chester) age [5] Bedding dips are usually gentle $\left(10^{\circ}\right.$ or less) except for some small local folds in the southwestern area of outcrop

A total of 65 oriented samples for paleomagnetic study were obtained from eight sites ( $F_{1} g$ 1) Many of our sampling sites correspond to localities previously sampled by Haas [5] and Howell and Martinez [2]

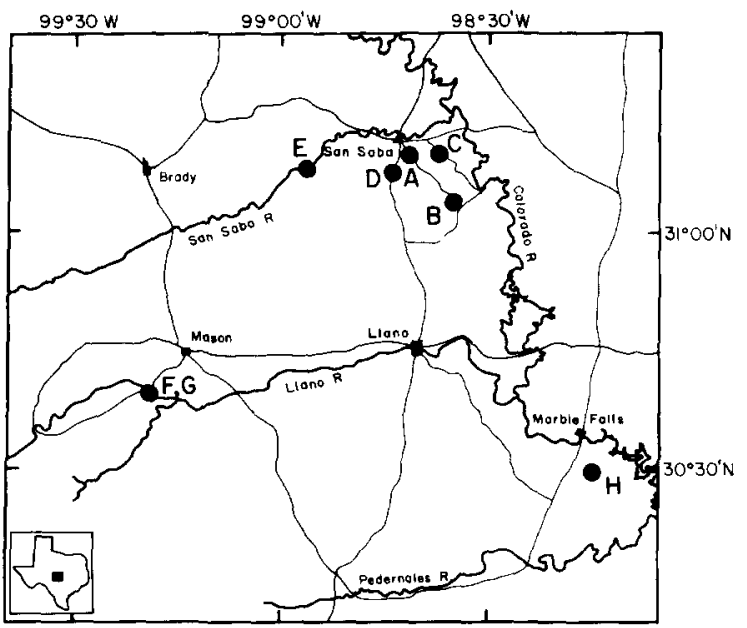

Fig 1 Location of paleomagnetic sampling sites of Barnett Formation
Wherever possible we sampled limy concretions, particularly since the brown shale was generally too friable to sample Two concretions (four samples) were collected at site $A$ (with the remaining samples taken in several calcareous beds), ten concretions (eleven samples) at site $B$, and seven concretions (seven samples) at site $C$ Shale was present at site $D$ but no concretions were exposed and only a calcareous bed was sampled The remaining sites $(E, F, G$, and $H)$ were located in exposures that consisted predominantly of light-colored limestones Stratıgraphic distribution of samples ranged from 1 to $2 \mathrm{~m}$ at site $C$ to approximately $5 \mathrm{~m}$ at site $A$, horizontal spread ranged to over $20 \mathrm{~m}$ (site $B$ and site $D$ )

\section{Paleomagnetısm}

Measurement of the natural remanent magnetization (NRM) was carried out with a 7-Hz computerized spinner magnetometer described by Molyneux [6]. Sample intensities ranged between $30 \times 10^{-7}$ and $03 \times$ $10^{-7} \mathrm{G}$, higher values typically associated with the calcareous concretions and low values with limestones The NRM directions of the samples are shown in Fig 2 A streaked distribution is evident between the present geomagnetic field direction and directions with southeastern declinations and shallow inclinations Closer inspection suggests two populations, one that has steep and northerly directions and another with shallower and southerly directions The latter grouping is similar to the distribution found by Howell and Martinez [2] and corresponds to the calcareous concretions and discrete calcareous beds at sites $A, B, C$ and $D$ The other population, corresponding to the very weakly magnetized limestones at the remaining sites, is evidently dominated by recent secondary magnetizations that could not be adequately removed by demagnetization as shown below

Demagnetızation diagrams obtained by progressive alternating field (AF) and thermal treatments are plotted in Fig 3 according to the Z1]derveld [7] method AF demagnetization performed on several pilot samples resulted in the initial removal of a component with a steep northerly direction, but a decay to the origin of a remaining vector could not be well established due to acquisition of spurious magnetizations at higher demagnetizing fields ( $F_{1} g$ 3d) Conse- 

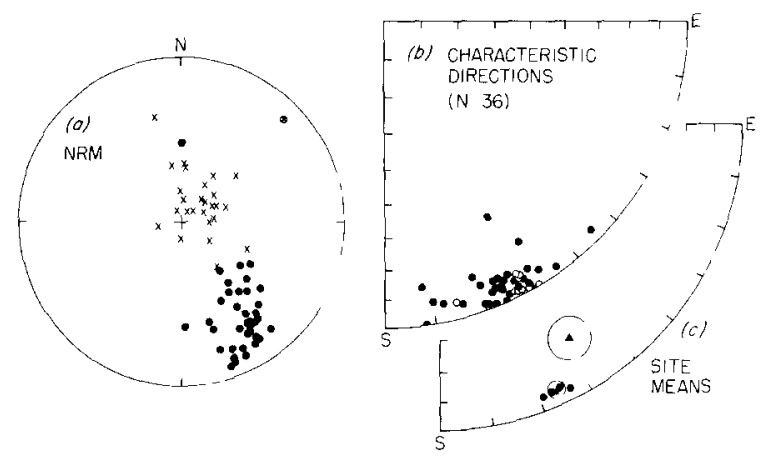

Fig 2 (a) NRM directions of sixty-five samples of the Barnett Formation Filled circles (crosses) are samples which gave reliable (unreliable) results after demagnetization Hexagon symbol corresponds to direction of geocentric axial dipole magnetic field at sampling locality All directions plotted on lower hemisphere of equal-area projection except encrrcled cross which is on upper hemisphere (b) Characteristic direction obtained by thermal demagnetization Filled (open) symbols on lower (upper) hemisphere qudrant of equal-area projection. (c) Site mean characteristic directions with formation mean (star symbol) and curcle of $95 \%$ confidence Triangle symbol is mean direction of Barnett Formation from Martınez and Howell [8] based on NRM only

quently, all remaining samples were analyzed by thermal techniques which allowed complete demagnetization Generally, above temperatures of $250^{\circ} \mathrm{C}$ the trajectory of further demagnetization was linear towards the origin until the magnetization drops below the noise level by $500^{\circ} \mathrm{C}$ (Fig 3a, b, c) This last trajectory is interpreted as the removal of a single, remaining magnetization which on the basis of the similar direction from sample to sample can be considered characteristic of these rocks

The magnetizations removed at low temperatures are more variable in direction from sample to sample although they typically have steep downward inclinations, and in many cases northerly declinations that suggest acquisition in the present-day geomagnetic field Curvature in the demagnetization trajectories to somewhat higher temperatures on some samples (Fig 3b) is interpreted as due to a broader, although not complete overlap in the blocking temperature distribution of the secondary and characteristic components There may also be more complicated behavior, as for the sample shown in $F_{1 g} 3 \mathrm{c}$, which may reflect several secondary components These multiple low-temperature directions, however, are not consistent from sam- ple to sample and may reflect magnetizations acquired since sampling

All samples were demagnetized in a minimum of three temperature steps over $250^{\circ} \mathrm{C}$ to isolate the characteristic component However, only half of the sites collected (36 samples) yielded well-defined characteristic directions which are shown in $F_{1 g} 2 b$ and group very well about a mean of $D=1563^{\circ}, I=61^{\circ}$ (Table 1) These sites were from the northern area of outcrop where the calcareous concretions and interlayered brown shale that are typical of the Barnett Formation are present The site localities that did not give reliable paleomagnetic data represent exposures that were entirely limestone, mostly from the southern area of outcrop but also including one site $(E)$ in the northern area As described earlier, the 29 samples from these sites typically have low NRM intensities and directions that are near to the present-day magnetic field direction (Fig 2a) Progressive thermal demagnetization of these samples does however show a change in direction toward a shallow, southerly direction but there is considerable scatter and no stable end point is apparently reached before the magnetizations approach the noise level of the magnetom. eter (Fig 4a). The directions of all 29 samples after $250^{\circ} \mathrm{C}$ thermal treatment also show a tendency to lie in the southeastern quadrant (Fig $4 \mathrm{~b}$ ) There is some indication therefore that the same characteristic magnetization observed at the other sites is also present in these samples However, a characteristic component cannot be as effectively resolved because of its smaller relative contribution to the NRM, and because these samples have very weak initial magnetizations which limit the level of demagnetization with the avalable equipment

Martinez and Howell [8] studied thin sections of the Barnett Formation and found that the most likely ferromagnetic mineral present is hematite which they suggested formed as a result of oxidation of syngenetic pyrites However, we can find no positive indication of hematite in the magnetic properties of these rocks For example, saturation of 1sothermal remanence (IRM) is apparently achieved in only a few thousand oersteds (Fig 5a) whereas much higher fields are usually required if hematite is the dominant magnetic mineral The stability of NRM is comparable to that of saturation IRM and of anhysteretic remanence (ARM) (F1g 5b) which suggests that the NRM is car- 


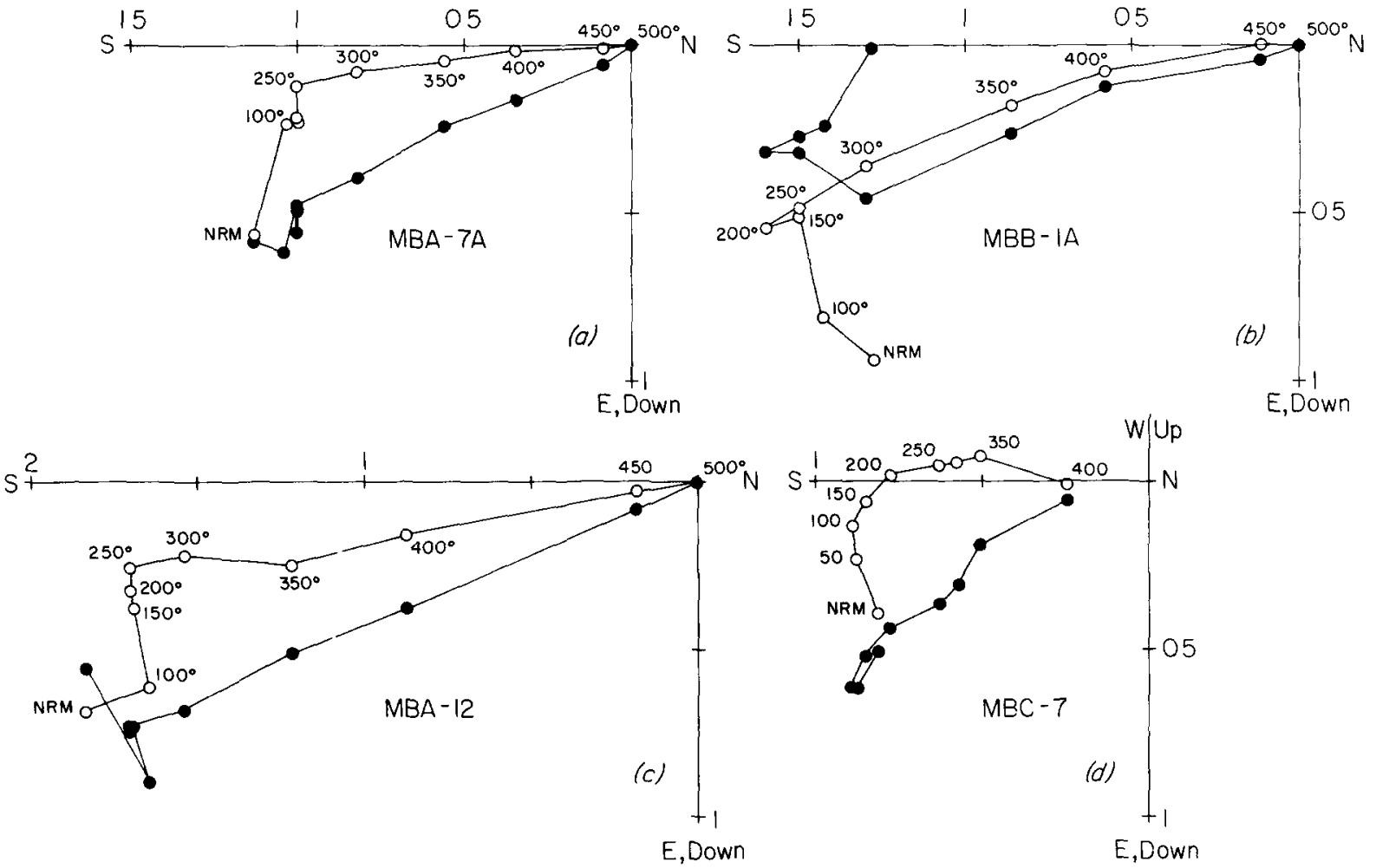

Fig 3 Vector demagnetization diagrams Closed (open) symbols are vector end points on horizontal (vertical) plane and adjacent numbers are demagnetization temperatures in (a), (b) and (c) and alternating field peak oersteds in (d) Axes are in units of $10^{-6} \mathrm{G}$ (a) and (b) are from calcareous concretions, (c) and (d) are from calcareous beds

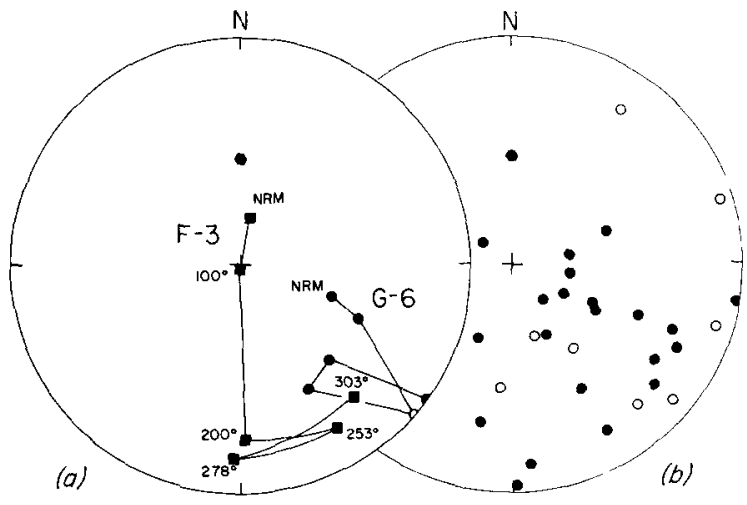

Fig 4 (a) Directional behavior of samples from rejected sites during progressive thermal demagnetization (b) Remanent directions after $250^{\circ} \mathrm{C}$ thermal demagnetization of 29 samples from rejected sites Closed (open) symbols on lower (upper) hemisphere of equal-area projection Hexagon symbol corresponds to direction of geocentric axial dipole magnetic field at sampling locality ried by a representative fraction of the total magnetic mineralogy, the relatively small differences in stability of these magnetizations may be related to the magnetic grain size [9] The inference that the NRM is representative of the same bulk magnetic mineralogy of these rocks that contributes to the IRM is supported by the similar thermal demagnetization curves of these magnetizations ( $\mathrm{F}_{1 \mathrm{~g}} \mathrm{5c}$ ) both of which ind1cate a distribution of blocking temperatures to about $500^{\circ} \mathrm{C}$ or less, far below the Curie point of hematite of $680^{\circ} \mathrm{C}$ Although the rock magnetic data can be interpreted to exclude hematite as a significant source of the rock magnetization, they do not provide strong positive evidence for any particular mıneral, like magnetite or possibly maghemite, with which they appear to be consistent On the other hand, some hematite may be present in the rocks but in insufficient quantity to be detected magnetically or to sensibly contribute to the NRM 
TABLE 1

Summary of characteristic magnetızations

\begin{tabular}{lrllrr}
\hline Site & $N$ & $\begin{array}{l}D \\
\left({ }^{\circ}\right)\end{array}$ & \multicolumn{1}{l}{$\begin{array}{l}I \\
\left({ }^{\circ}\right)\end{array}$} & \multicolumn{1}{c}{$\begin{array}{l}\alpha_{95} \\
()^{2}\end{array}$} & \multicolumn{1}{c}{$k$} \\
\hline MBA & 12 & 1553 & 69 & 56 & 60 \\
MBB & 11 & 1577 & 68 & 33 & 189 \\
MBC & 7 & 1535 & 45 & 43 & 197 \\
MBD & 6 & 1589 & 51 & 111 & 37
\end{tabular}

Mean of 4 sites $D=1563^{\circ}, I=58^{\circ}, \alpha_{95}=30^{\circ}, k=905$

Mean of 36 samples $D=1563^{\circ}, I=61^{\circ}, \alpha_{95}=26^{\circ}, k=82$

Pole position from site means lat $=491^{\circ} \mathrm{N}$, long $=1193^{\circ} \mathrm{E}$, $d p=15^{\circ}, d m=30^{\circ}$

$N$ is the number of samples, $D$ and $I$ are mean declination and inclination, $\alpha_{95}$ and $k$ are the semi-angle of the core of $95 \%$ confidence and the precision parameter, respectively [17], $d p$ and $d m$ are the semi-axes of the oval of $95 \%$ confidence around the mean pole position, along the paleomeridian and perpendicular to it, respectively Note that all samples collected from each of the sites are included in calculation of site mean directions whereas 29 samples from four other sites have been excluded due to unstable magnetızation

\section{Discussion of results}

The site mean characteristic directions for the four sites which gave reliable data are summarized in Table 1 and shown in $F_{1}$ 2c These give a formation mean of $D=1563^{\circ}, I=58^{\circ}\left(k=905, \alpha_{95}=30^{\circ}\right)$ which is essentially the same mean direction calculated from the 36 sample directions Although we have rejected half of the sites collected, we consider the derived mean direction representative of the Barnett Formation The samples which yielded characteristic magnetizations are all from sites where the lithology is typical of the Barnett in its type area, that is, a brown shale with calcareous concretions and discrete calcareous beds, whereas the rejected sites come from a more atypical, limestone lithology The rejection criteria were based on a certain instability of the individual samples durnng demagnetization that was in large part related to the very weak remanent intensities of the limestones, which we feel prohibited the complete removal of an apparently dominant secondary component near the present-day field direction No different characteristic magnetization direction is suggested in the limestones and indeed there are indications that it is similar to that at the accepted sites In other
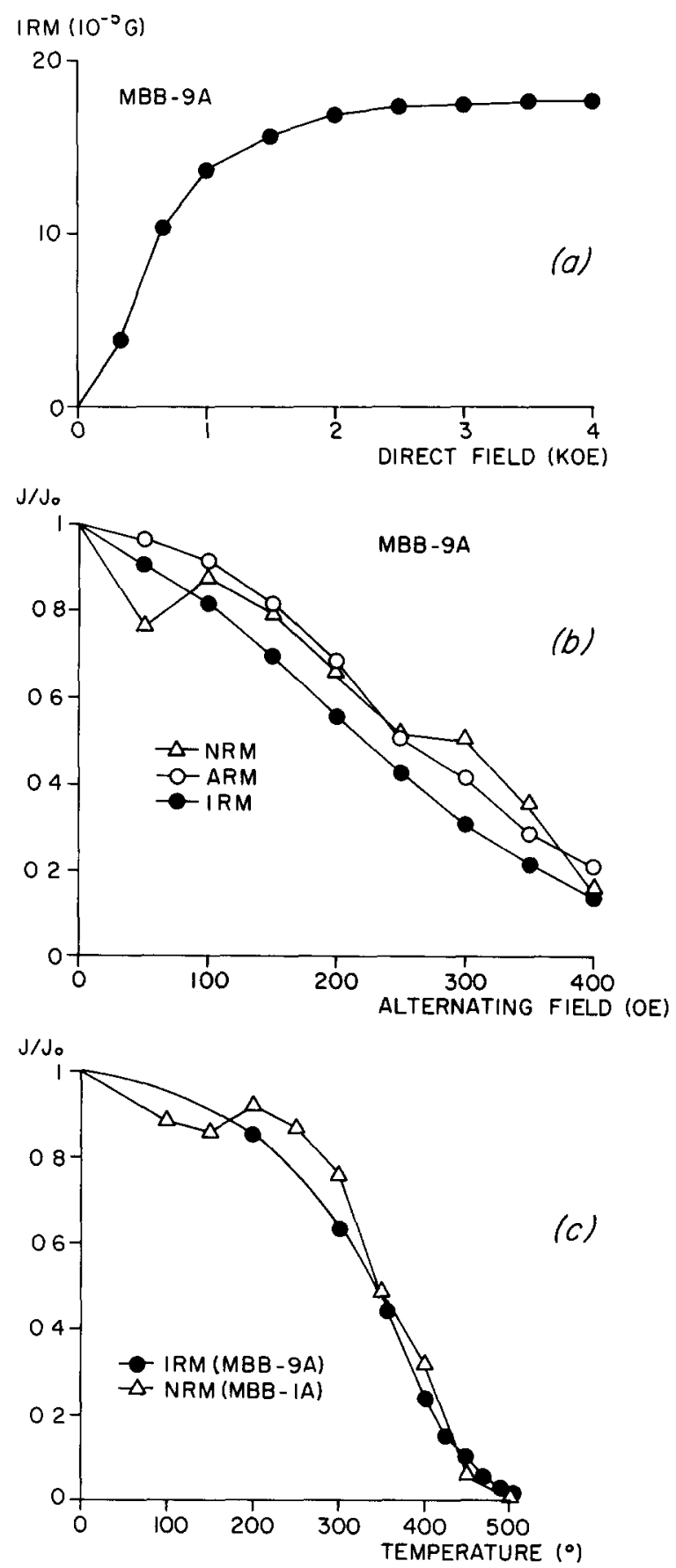

Fig 5 (a) Acquisition curve of isothermal remanent magnet1zation (IRM) (b) Normalized AF demagnetization curves of natural (NRM), anhysteretic (ARM, 10 Oe, $2000 \mathrm{Oe} \mathrm{AF)} \mathrm{and}$ 1sothermal (IRM, $2000 \mathrm{Oe}$ ) remanent magnetizations (c) Thermal demagnetization of NRM and IRM All samples are from calcareous concretions 
words, the difference in magnetic behavior is probably simply related to lithologic differences

The formation mean direction we obtain is near to but is shallower than the mean reported by Howell and Martinez [2] (Fig 2c) This difference is predictable because they measured only NRM which was probably contaminated by a secondary component in the present-day field direction The close agreement between the two studies is impressive nonetheless considering the weak magnetization of these rocks and the early date of the initial work Unfortunately we were not able to relocate site $J$ of Howell and Martinez [2] which gave shallow, northerly directions Our effort at site $E$, the presumed location of their site, did not yield reliable data

There is no reason to suspect that the characteristic direction was not acquired during Early Carboniferous (Mississippian) tıme Moreover, although a fold test is not possible to limit the age of the magnetization, other field evidence can be interpreted to support an origin early in the history of the rocks In particular, the calcareous concretions are evidently syngenetic and were formed prior to compaction of the surrounding sediment, as indicated by the bending of bedding surfaces around them It is therefore likely that the remanent magnetization of the concretions was also acquired prior to compaction The magnet1zation may be some form of chemical remanence related to the processes that formed the concretions, as suggested by Martınez and Howell [8] Alternatively, the concretions have locked-in and preserved a depositional remanence in the enveloped part of the shales Traces of what appear to be original bedding lamınae can bee seen within the concretions and give some support to this mechanism In elther case, there is good agreement between the results obtained from all of the concretions and from the discrete calcareous beds at the same and nearby sites The between-site directions, is smaller than the within-site dispersion in directions, suggesting that paleosecular variation is averaged by the stratigraphic distribution of samples at each site and perhaps to some extent within individual samples as well Finally, later remagnetization is considered unlikely because the underlying Wilberns Formation is apparently unaffected since it gives directions consistent with other Late Cambrian paleomagnetic data and $90^{\circ}$ away from the Barnett characteristic direct1ons [10]

\section{Comparison with other data}

The mean direction from the four site means corresponds to a paleomagnetic (north) pole position, assuming this magnetization is of reversed polarity, at lat $=491^{\circ} \mathrm{N}$, long $=1193^{\circ} \mathrm{E}\left(d p=15^{\circ}, d m=\right.$ $30^{\circ}$ ) There are surprisingly few other published results for the Lower Carboniferous of North America for comparison, particularly those which meet reasonable minimum reliability criteria Those paleomagnetic poles that are based on at least some demagnetization analysis are plotted with respect to the Late Paleozorc segment of the apparent polar wander path for stable North America in Fig 6

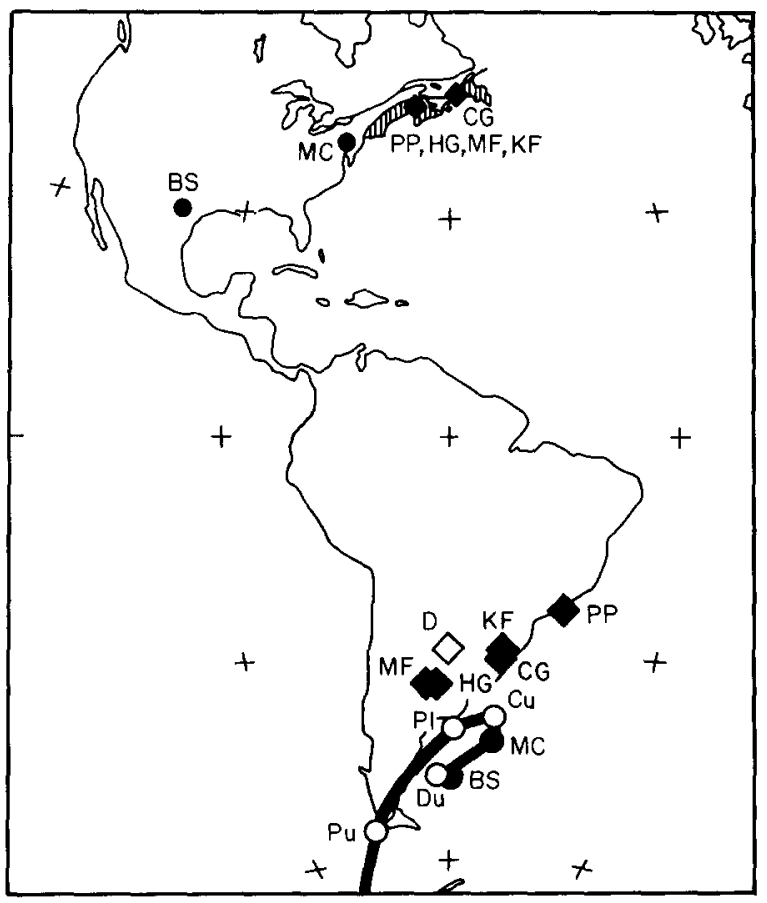

Fig 6 Lower Carboniferous paleomagnetic south poles and sampling localities from stable North America (filled curcles) and Acadia (filled diamonds) compared to Late Paleozoic apparent polar wander path for stable North America (open curcles, $\mathrm{Du}=$ Upper Devonian, $\mathrm{Cu}=$ Upper Carboniferous, Pl = Lower Permian, $\mathbf{P u}=$ Upper Permian) [14] Acadia displaced terrain is sketched with shading $M F=$ Maringouin Formation [18], HG = Hopewell Group [19], CG = Codroy Group, $\mathrm{KF}=$ Kennebecasis Formation, $\mathrm{PP}=$ pre-Pictou sediments [11], MC = Mauch Chunk Formation [20], BS = Barnett Formation (this paper) $D$ (open diamond) = mean Devonian pole for Acadia from Kent and Opdyke [1] 
The principal observation is that all the avalable Early Carboniferous (Mississippian) paleopoles from Acadia lie consistently away from the relevant portion of the North American apparent polar wander path This is in contrast to the paleopoles for the Barnett Formation, and the Mauch Chunk Formation, a clast1c unit exposed in the folded Appalachians that was deposited on the margin of the North American craton [20] Both of these poles lie near the shortest distance join between the mean Late Devonian and Late Carboniferous poles for stable North America and can be considered to provide additional constraints on this portion of the apparent pole path Perhaps the statıstically significant difference between the Barnett and the Mauch Chunk paleopoles is related to the difference in age of the two formations The Barnett, whose pole is near the Late Devonian mean, is at least in part of Early Mississippian age whereas the Mauch Chunk 1s younger, of Late Mississippian age, and its pole falls closer to the mean Late Carboniferous (Pennsylvanian) position This would imply some $8^{\circ}$ of apparent polar shift for North America during Mississippian time but this suggestion obviously needs confirmation

The Early Carboniferous paleopoles from Acadia are somewhat scattered but fall consistently at lower latitudes than nearly contemporaneous or younger poles from stable North Amertca The paleomagnetic results from the Maringouin Formation (MF) and the Hopewell Group (HG) of New Brunswick are each well determined experimentally and it is noteworthy that their pole positions are in very close mutual agreement Together these two paleopoles, which can be considered the best avallable data for Lower Carboniferous rocks of Acadia, differ by some $12^{\circ}$ or $15^{\circ}$ frorn the Mauch Chunk or Barnett paleopoles The other Early Carboniferous paleopoles from Acadia (PP, KF, Fig 6) diverge from the Marıngouin and Hopewell poles but in a sense that makes them differ even more widely from the Barnett and Mauch Chunk poles of stable North Amwrica The divergence of these poles may well be related to poor experimental control in these early studies [11] For example, the result for the pre-Pictou sediments (PP) was based on just eight samples and the alternating field treatment applied in the study of these redbeds and those of the Kennebecasis Formation (KF) may not have been adequate to remove secondary components and to solate a characteristic magnetization
An interesting exception to the overall pattern of Lower Carboniferous paleopoles is the paleomagnetic result from the Codroy Group of Newfoundland ([11], CG in Fig 6) This paleopole should lie near the Barnett or the Mauch Chunk pole if western Newfoundland in fact belongs to North America (e g [12]) but instead the Codroy pole falls within the cluster of pole positions from the Acadia displaced terrain We again question the adequacy of the experimental procedures in obtaining this result from the Codroy redbeds ( $1 \mathrm{e}$, no thermal demagnetization) and note that Nairn et al [13] earlier had derived a paleomagnetic pole position from Codroy Group rocks using similar techniques that is more compatible with other stable North American data The discrepancy between the two studies suggests renewed investigations using modern standards of demagnetization analysis may be worthwhile to verify some of these early results

\section{Conclusions}

The difference in Early Carboniferous paleopoles between Acadia and stable North America is similar in magnitude and sense to the difference in Devonian paleopoles we [1] have earher described (Fig 6) As far as can be estimated this difference is no longer apparent by the Late Carboniferous when paleopoles of this age that are avalable show reasonable agreement $[1,14]$ We have interpreted the difference in paleopoles as evidence for original separation between the two areas and the agreement in younger paleopoles as indicative of the time the displaced terrain reached its present position with respect to North America [1] Our study of the Barnett Formation lends support to the idea that Acadia was still far $(\sim 1500 \mathrm{~km})$ from its present position relative to stable North America in the Early Carboniferous and consequently the relative motion of this displaced terrain with respect to North America must have occurred in a rather short tıme within the Carboniferous Since there is little evidence of any closed or subducted oceans of Carbonfferous age in the northern Appalachians, we assume the relative motion was taken up predominantly along shear zones This is consistent with evidence for extensive Carboniferous strike-slip faulting in the Canadian Maritimes [15] If the relative motion ( $1500 \mathrm{~km})$ occurred over say one-thırd ( $20 \mathrm{~m} \mathrm{y}$ ) of the duration 
of the Carboniferous ( $\sim 60 \mathrm{~m}$ y [16]), an average rate of $75 \mathrm{~cm} / \mathrm{yr}$ would have been required This rough estımate compares favorably to present-day rates of relative motion between lithospheric plates The geological consequences of this relative motion and the possible involvement of other continents remain to be explored

\section{Acknowledgements}

We thank F Chamalaun and R A Schweıckert for critical reviews of the manuscript This research was supported by the National Science Foundation, Grant EAR75-18955 Lamont-Doherty Geological Observatory Contribution No 2837

\section{References}

1 D V Kent and N D Opdyke, Paleomagnetism of the Devonıan Catskill Red Beds evidence for motion of coastal New England-Canadian Maritime region relative to cratonic North America, J Geophys Res 83 (1978) $4441-4450$

2 L G Howell and J D Martinez, Polar movement as ind1cated by rock magnetism, Geophysics 22 (1957) 384397

3 P B King, The Evolution of North America (Princeton Unıversity Press, Princeton, N J , 1977) $197 \mathrm{pp}$

4 P E Cloud, $\mathrm{Jr}$ and V E Barnes, The Ellenburger group in central Texas, Univ Texas Publ 4621 (1948) 42-60

5 W H Haas, Conodonts of the Barnett Formation of Texas, U S Geol Surv Prof Paper 243-F (1952) 69-94

$6 \mathrm{~L}$ Molyneux, A complete result magnetometer for measuring the remanent magnetization of rocks, Geophys $\mathbf{J}$ R Astron Soc 10 (1971) 429

7 J D A Z 1 jderveld, A C demagnetization of rocks analysis of results, in Methods in Paleomagnetısm, D W Collinson,
K M Creer and S K Runcorn, eds (Elsevier, Amsterdam, 1967) 254-286

8 J D Martinez and L G Howell, Paleomagnetism of chem1cal sediments, Nature 178 (1956) 204-205

9 H P Johnson, W Lowrie and D V Kent, Stability of anhysteretic remanent magnetization in fine and coarse magnetite and maghemite particles, Geophys J R Astron Soc 41 (1975) 1-10

10 R Van der Roo, R B French and D W Willams, Paleomagnetism of the Wilberns Formation (Texas) and the Late Cambrian paleomagnetic field for North America, J Geophys Res 81 (1976) 5633-5638

11 R F Black, Paleomagnetic support of the Theory of Rotation of the Western Part of the Island of Newfoundland, Nature 202 (1964) 945-948

$12 \mathrm{H}$ Williams and R K Stevens, The ancient continental margin of North America, in The Geology of Continental Margins, C A Burke and C L Drake, eds (Springer-Verlag, New York, N Y , 1974) 781-796

13 A E M Nairn, D V Frost and B G Light, Paleomagnetısm of certain rocks from Newfoundland, Nature 183 (1959) 596-597

14 E Irving, Paleopoles and paleolatitudes of North America and speculations about displaced terrains, Can $J$ Earth $\mathrm{Sc1}$ (in press)

$15 \mathrm{GW}$ Webb, Paleozorc wrench faults in Canadian Appalachians, in North Atlantic - Geology and Contınental Drift, A Symposium, M Kay, ed, Assoc Pet Geol, Mem 12 (1969) 754-788

16 F W B Van Eysınga, (compler), Geologıcal Time Table (Elsevier, Amsterdam, 1975) 3rd ed

17 R A Fisher, Dispersion on a sphere, Proc R Soc London, Ser A, 217 (1953) 295-305

$18 \mathrm{~J} \mathrm{~L}$ Roy and W A Robertson, Evidence for diagenetic remanent magnetization in the Maringoum Formation, Can J Earth Sc1 5 (1968) 275-385

19 J L Roy and J K Park, Paleomagnetssm of the Hopewell Group, New Brunswick, J Geophys Res 74 (1969) 594 604

20 R R Knowles and N D Opdyke, Paleomagnetic results from the Mauch Chunk Formation a test of the origin of curvature in the folded Appalachians of Pennsylvania, J Geophys Res 73 (1968) 6516-6526 